\section{Jejunal diverticular bleeding treated with hemoclips at double-balloon enteroscopy}

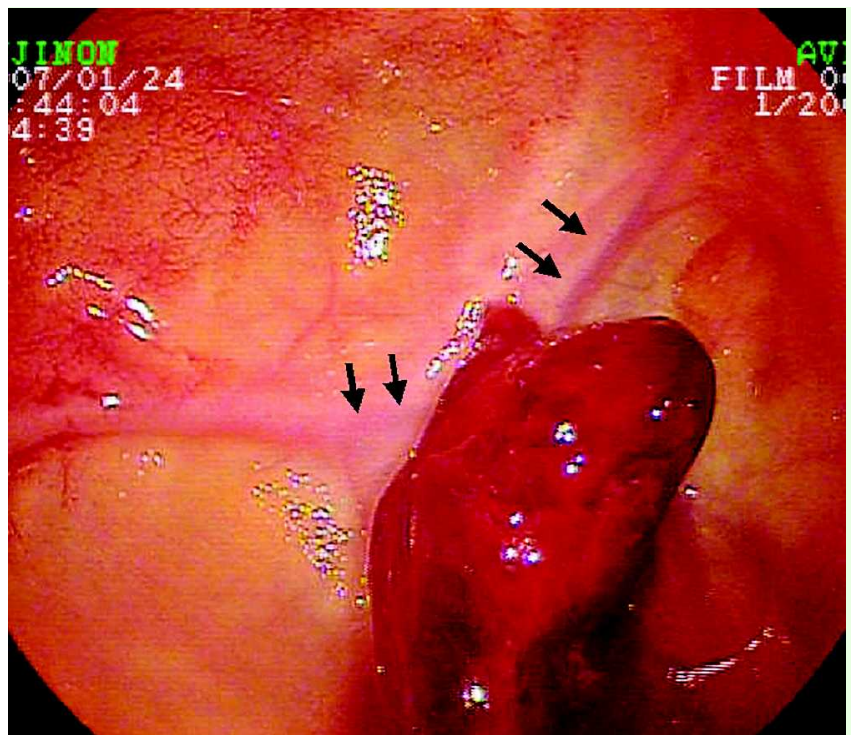

Fig. 1 An endoscopic view of the blood clot adhering to a jejunal diverticulum $20 \mathrm{~cm}$ distal to the ligament of Treitz. Linear submucosal vessels (arrows) could be traced proximal to the bleeding site.

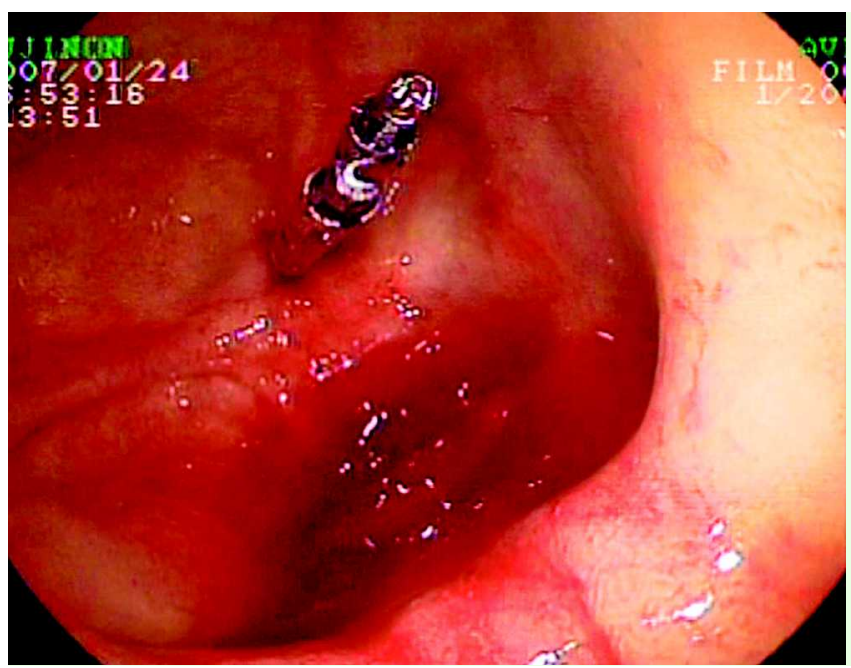

An 80-year-old man was referred for evaluation of melena and hematochezia. The initial esophagogastroduodenoscopy, a colonoscopy, and a computed tomographic scan all failed to identify the source of the bleeding. Double-balloon enteroscopy was performed using the oral approach (EN-450T5/20; Fujinon Co. Ltd., Saitama, Japan). A blood clot adhering to a jejunal diverticulum was found $20 \mathrm{~cm}$ distal to the ligament of Treitz and linear submucosal vessels could be traced proximal to the bleeding point ( $\bullet$ Fig. 1). Two endoclips (Resolution Clip; Boston Scientific Co., Natick, Massachusetts, USA) were deployed on the feeding vessels. A blood clot was removed with tripod grasping forceps and the diverticulum was gently irrigated with water. We were then able to confirm that the bleeding had stopped ( Fig. 2, Video 1). The patient had no further episodes of bleeding during his hospital stay and was discharged.

Although massive bleeding from a jejunal diverticulum is extremely rare, surgery has traditionally been the treatment of choice, with or without identification of the bleeding site [1]. However, studies have suggested that endoscopic therapy could be an initial treatment option in colonic diverticular disease [2,3], and endoscopic hemostasis of diverticular bleeding in the small bowel could be possible during double-balloon enteroscopy. When applied to the thin dome of a diverticulum, thermal endoscopic hemostatic treatments could carry a high risk of perforation. Endoclipping would be the mod-

\section{Video 1}

Two endoclips were deployed on the feeding vessels. The bleeding stopped after a blood clot was removed with tripod grasping forceps and the diverticulum was gently irrigated with water. 
ality least likely to cause trauma. Effective hemostasis with hemoclips was achieved in this case by direct deployment on the feeding vessels, which were easily identified through the thin mucosa of the diverticulum. However, diverticular bleeding of the small bowel is extremely rare and experience with endoscopic hemostasis has been limited $[4,5]$. To our knowledge, this is the first description of endoscopic hemoclipping being used to control jejunal diverticular bleeding. In conclusion, endoscopic clip application can be a safe and effective therapeutic option for diverticular bleeding in the small bowel.

Endoscopy_UCTN_Code_TTT_1AP_2AD
S.H. Eun, J. O. Kim, B. M. Ko, J. Y. Cho, J. S. Lee, M. S. Lee, C. S. Shim

Institute for Digestive Research, Soonchunhyang University, College of Medicine, Seoul, Korea

\section{References}

1 Longo WE, Vernava AM $3^{\text {rd }}$. Clinical implications of jejunoileal diverticular disease. Dis Colon Rectum 1992; 35: 381 - 388

2 Lara LF, Bloomfeld RS. Endoscopic therapy for acute diverticular hemorrhage. Gastrointest Endosc 2001; 53: 492

3 Yoshikane H, Sakakibara A, Ayakawa T et al. Hemostasis by capping bleeding diverticulum of the colon with clips. Endoscopy 1997; 29: S33-S34

4 Raju GS, Nath S, Zhao X et al. Duodenal diverticular hemostasis with hemoclip placement on the bleeding and feeder vessels: a case report. Gastrointest Endosc 2003; 57: $116-117$

5 Rioux L, Des Groseilliers S, Fortin M, Mutch DO. Massive upper gastrointestinal bleeding originating from a fourth-stage duodenal diverticulum: a case report and review of the literature. Can J Surg 1996; 39: 510 512
Bibliography

DOI 10.1055/s-2007-967053

Endoscopy 2009; 41: E29-E30

(c) Georg Thieme Verlag KG Stuttgart · New York . ISSN 0013-726X

Corresponding author

\section{J. O. Kim, MD}

Institute for Digestive Research

Soonchunhyang University

College of Medicine

657 Hannam-dong

Yongsan-gu

Seoul 140-743

South Korea

Fax: +82-27099696

jokim31@hanafos.com 